\title{
Role of autophagy on cancer immune escape
}

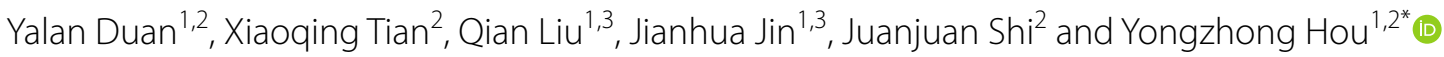

\begin{abstract}
Autophagy is catabolic process by degradation of intracellular components in lysosome including proteins, lipids, and mitochondria in response to nutrient deficiency or stress such as hypoxia or chemotherapy. Increasing evidence suggests that autophagy could induce immune checkpoint proteins (PD-L1, MHC-I/II) degradation of cancer cells, which play an important role in regulating cancer cell immune escape. In addition to autophagic degradation of immune checkpoint proteins, autophagy induction in immune cells (macrophages, dendritic cells) manipulates antigen presentation and T cell activity. These reports suggest that autophagy could negatively or positively regulate cancer cell immune escape by immune checkpoint protein and antigens degradation, cytokines release, antigens generation. These controversial phenomenon of autophagy on cancer cell immune evasion may be derived from different experimental context or models. In addition, autophagy maybe exhibit a role in regulating host excessive immune response. So rational combination with autophagy could enhance the efficacy of cancer immunotherapy. In this review, the current progress of autophagy on cancer immune escape is discussed.
\end{abstract}

Keywords: Autophagy, Immune cells, Immune escape, Antigen presentation, Cancer therapy

\section{Background}

Autophagy is the intracellular components (proteins, lipids, mitochondria, nucleus etc.) degrading process in lysosome in response to stressful conditions such as nutrition deficiency, hypoxia, and chemotherapy, which is also nutrients recycling [1]. Autophagy contains three types including macroautophagy, microautophagy, and chaperone-mediated autophagy (CMA). Macroautophagy process undergoes initiation, nucleation, vesicle expansion, maturation of autophagosome, fusion of autophagosome-lysosome and finally degradation of components in lysosome [2-4]. In microautophagy process, proteins and organelles are degraded by direct engulfment of lysosomes [4]. In CMA process, proteins with KFERQ motif are recognized by HSC70 (heat shock cognate $70 \mathrm{kDa}$ protein) resulting in targeted proteins

*Correspondence: houyz@ujs.edu.cn

${ }^{1}$ Department of Oncology, The Affiliated Wujin Hospital, Jiangsu University, Changzhou 213017, Jiangsu Province, China

Full list of author information is available at the end of the article degradation in lysosome by LAMP2A ( lysosomal-associated membrane protein 2A) [5]. Autophagy (hereafter referred to as macroautophagy) degrades misfolded proteins or dysfunctional organelles to maintain cellular homeostasis [1]. The autophagy receptors such as p62 (SQSTM1) and NBR1 (next to BRCA1 gene 1 protein) mediate ubiquitinated proteins for autophagic degradation leading to clearance of misfolded proteins $[6,7]$. In addition, PINK1 induces ubiquitin phosphorylation leading to activation of PARKIN ubiquitin ligase, consequently facilitates ubiquitination of mitochondrial outer membrane proteins resulting in autophagy receptors (NDP52 and optineurin)-mediated damaged mitochondrial degradation [8]. Dysregulation of autophagy has been implicated in cance [9-12]. Although autophagy promotes cancer cell survival under nutrient and oxygen deprivation by degrading a bulk of organelles, proteins, and lipids for nutrients recycling [10,11, 13-16], the role of autophagy in cancer progression is dependent on the conditions such as the tumor types and tumor models used [9-11]. Furthermore, autophagy plays an important original author(s) and the source, provide a link to the Creative Commons licence, and indicate if changes were made. The images or other third party material in this article are included in the article's Creative Commons licence, unless indicated otherwise in a credit line to the material. If material is not included in the article's Creative Commons licence and your intended use is not permitted by statutory regulation or exceeds the permitted use, you will need to obtain permission directly from the copyright holder. To view a copy of this licence, visit http://creativecommons.org/licenses/by/4.0/. The Creative Commons Public Domain Dedication waiver (http://creativeco mmons.org/publicdomain/zero/1.0/) applies to the data made available in this article, unless otherwise stated in a credit line to the data. 
role in regulating cancer immunotherapy by degrading immune checkpoint proteins [17, 18]. Increasing clinical evidence shows that immunotherapy is an exciting benefit for variety of tumors, while it exhibits low response rates for patients, suggesting that cancer immunotherapy is so complicated and the mechanisms could be associated with cancer types and individual difference [19]. Similarly, autophagy could negatively or positively regulate cancer immunotherapy by degradation of immune checkpoint protein, pro-inflammatory cytokines release, and antigens generation or degradation $[17,18$, 20-26]. For example, in cancer cells, induction of PD-L1 autophagic degradation promotes $\mathrm{T}$ cell killing of cancer cells and enhances the efficacy of cancer immunotherapy [17], whereas MHC-I undergoes autophagic degradation in pancreatic ductal adenocarcinoma (PDAC) leading to loss of antigen presentation to $\mathrm{T}$ cells, consequently inhibits cancer immunotherapy [18]. However, the contradictory role of autophagy on cancer cell immune evasion may be derived from different experimental context or models. Autophagy maybe exhibit a role in regulating host excessive immune response. In this review, we discussed the current progress of autophagy on cancer immune escape.

\section{Autophagy regulates PD-1/PD-L1 immune checkpoint pathway}

Expression of PD-L1 on cancer cells binds to PD-1 on T cells leading to inhibition of $\mathrm{T}$ cell activation and proliferation, consequently promotes cancer immune escape [27, 28]. Therefore, PD-1/PD-L1 immune checkpoint blockade can enhance the efficacy of cancer immunotherapy 29, 30. Although cancer cell exhibits immune evasion by abnormal expression of PD-L1 [30, 31], deficiency of HIP1R in cancer cells increases PD-L1 protein levels [32]. In this study, it shows that HIP1R acts as a autophagy receptor for PD-L1 binding and induces PD-L1 selective autophagic degradation in lysosome, subsequently, inhibits tumor growth by increasing $\mathrm{T}$ cell cytotoxicity, suggesting that autophagic degradation of PD-L1 suppresses cancer immune escape. However, cancer cell exhibits ability to inhibit PD-L1 autophagic degradation by transcriptional modification [33, 34]. EGFR/B3GNT3 pathway-induced PD-L1 glycosylation leads to inhibition of PD-L1 autophagic degradation, subsequently, facilitates tumor immune escape in a breast xenograft tumor model [33]. PD-L1 palmitoylation by DHHC3 reduces PD-L1 endosomal sorting-mediated autophagic degradation consequent immune suppression and tumor growth in a colon tumor model [34]. In addition to PD-L1 protein modification, the cell membrane CMTM6 binds to PD-L1 consequent inhibition of endocytosed PD-L1 degradation and tumor immune evasion [35]. Therefore, in response to extracellular stimuli, activation of autophagy induces PD-L1 degradation in lysosome, subsequently, increases the efficacy of cancer immunotherapy [34, 36, 37]. SA-49 treatment facilitates PKC $\alpha /$ GSK $3 \beta / M I T F-$ mediated PD-L1 autophagic degradation [36], and DHHC3 inhibitor 2-bromopalmitate (2-BP) abolishes PD-L1 palmitoylation resulting in PD-L1 autophagic degradation [34], subsequently, enhances the efficacy of cancer immunotherapy in a colon tumor model. Moreover, verteporfin induces PD-L1 degradation in Golgi-related autophagy pathway consequent $\mathrm{T}$ cell activation [38]. As a phase III trial drug, sunitinib promotes p62-mediated PD-L1 autophagic degradation resulting in increased anti-tumor immune response [39]. Since the interaction of SIGMA I with glycosylated PD-L1 leads to inhibition of PD-L1 autophagic degradation in breast and prostate cancer cells, SIGMA I inhibitor IPAG reverses this event leading to increased $\mathrm{T}$ cell activity [37]. In addition to autophagy induction by extracellular stimuli, PD-L1 blockade by PD-L1 antibody H1A inhibits the interaction of PD-L1 with CMTM6 leading to PD-L1 autophagic degradation [40]. These findings suggest that autophagy induction causes selective PD-L1 autophagic degradation, subsequently, increases T cell activity (Fig. 1). However, another study suggests that autophagy activation increases PD-L1 expression by $5-\mathrm{HT} 1 \mathrm{aR} /$ autophagy/pSTAT3 pathway in lung adenocarcinoma patients with depression leading to immune escape [41]. Similarly, pharmacological inhibition of PIK3C3/VPS34-mediated autophagy increases the efficacy of immunotherapy by PD-1/PD-L1 immune checkpoint blockade [42]. These findings suggest that rational PD-L1 levels could improve PD-1/PD-L1 blockade therapy.

\section{Autophagy and MHC-I/MHC-II}

Activation of innate and adaptive immune response is critical for killing to cancer cells in host immune system $[43,44]$. In this process, MHC-I/II plays an important role on antigen presenting cells (APCs) by presenting antigens to $\mathrm{T}$ cells consequent $\mathrm{T}$ cell activation $[43,44]$. However, cancer cell can escape immune surveillance by degrading MHC-1 [18]. In pancreatic ductal adenocarcinoma (PDAC), MHC-I proteins are selective degradation by NBR1, subsequently, reduces antigen presentation and $T$ cell killing to cancer cells. In contrast, autophagy inhibitors treatment enhances the efficacy of anti-tumor therapy [18]. Similarly, March1 E3 ubiquitin ligase induces MHC-II autophagic degradation in M-MDSCs (myeloid-derived suppressor cells) leading to cancer immune evasion. Conversely, autophagy inhibition by ATG5 deficiency elevates cell surface MHC-II protein levels leading to increased $\mathrm{CD} 4^{+} \mathrm{T}$ cell activation [45]. Although one study shows that autophagy activation in response 


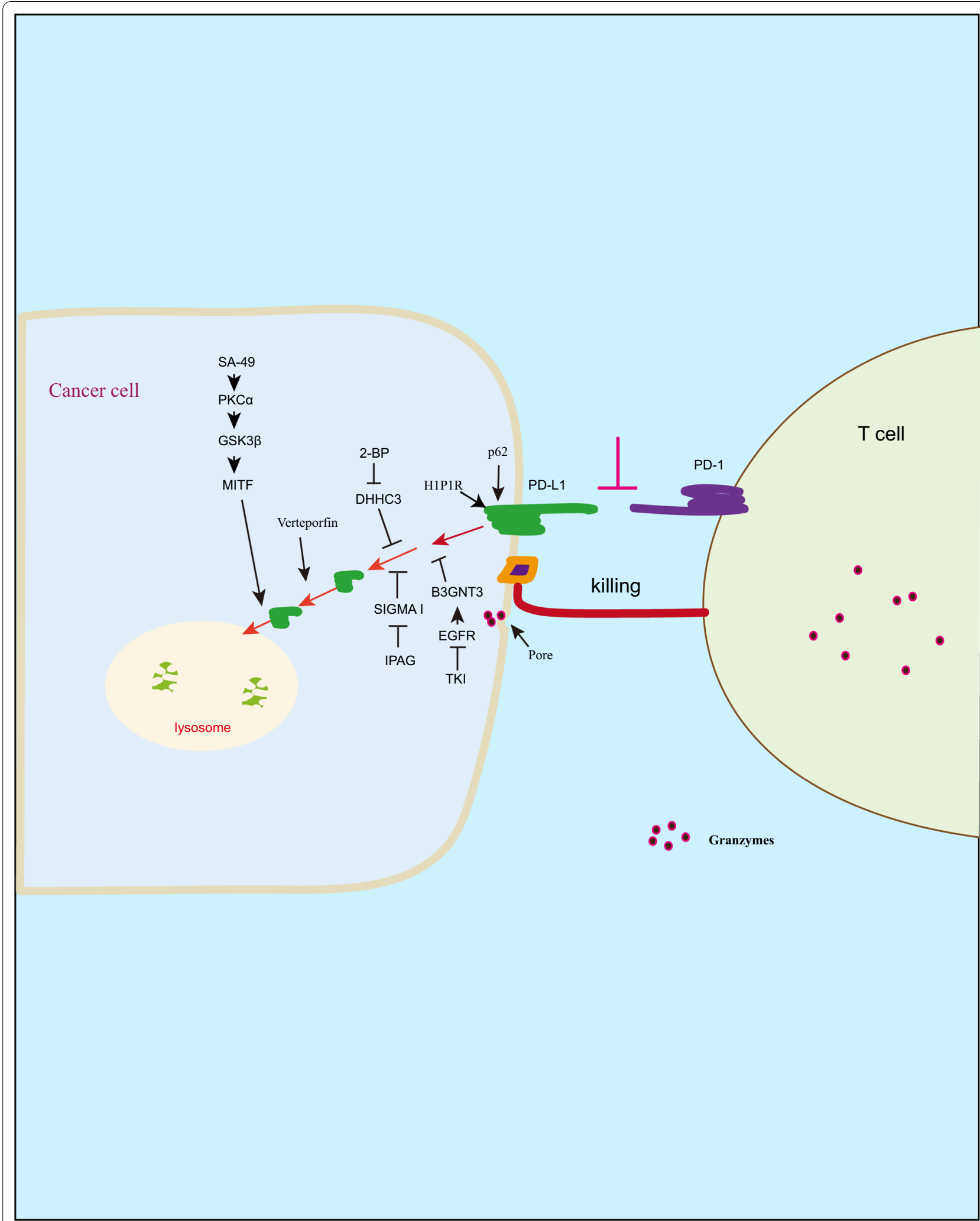

Fig. 1 Autophagy regulates PD-1/PD-L1 immune checkpoint pathway. The binding of PD-L1 to PD-1 suppresses T cell killing to cancer cells, while PD-L1 undergoes selectively autophagic degradation by H1P1R or p62. In addition, autophagy could be activated by extracellular stimuli such as SA-49, 2-BP, veteporfin resulting in PD-L1 autophagic degradation in cancer cells, consequently, enhances T cell activity and inhibits tumor growth 
to irradiation increases MHC-I expression and $\mathrm{CD} 8^{+} \mathrm{T}$ cell infiltration in NSCLC cells, the direct relationship of $\mathrm{MCH}-1$ expression with autophagy is unclear [46]. In addition to degradation of MHC-1 in cancer cells, AAK1 mediates MHC-1 endocytosis and autophagic degradation in DCs resulting in inhibition of antigen presentation and $\mathrm{CD} 8^{+} \mathrm{T}$ cell priming, which is reversed in DCs by deficiency of autophagy [47]. These findings suggest that autophagic degradation of MHC-I/II in cancer cells facilitates tumor immune evasion (Fig. 2). However, in the tumor microenvironment, could cancer cell regulate MHC-1 autophagic degradation in DCs?

\section{Mitophagy and tumor immune escape}

Mitophagy is a selective autophagy process by clearance of damaged or dysfunctional mitochondria, which is triggered in response to stimuli such as hypoxia, DNA damage, and nutrient starvation [48]. Mitophagy plays an important role in regulating immune response against cancer [49-51]. Increased mitophagy in STAT3 deleted intestinal epithelial cells facilitates lysosomal membrane permeabilization by increasing $\mathrm{Fe}^{2+}$ accumulation, which in turn releases cathepsin into cytosol and generates peptides for antigen presentation, leading to $\mathrm{T}$ cell activation and anti-tumor immunity [49]. PINK1/PARK2 pathway-mediated mitophagy is essential for clearance of damaged mitochondria and inhibits tumor development [50]. Deficiency of Pink1 and Park2 promotes pancreatic tumorigenesis in Kras-driven tumor model by increasing mitochondrial iron accumulation and AIM2/ HMGB1 pathway-mediated PD-L1 expression [51]. As a mitophagy receptor, FUN14 domain-containing 1 (FUNDC1)-mediated mitophagy inhibits hepatocellular carcinoma (HCC) initiation and progression in response to diethylnitrosamine, whereas hepatocyte-specific FUNDC1 deficiency increases dysfunctional mitochondria accumulation and cytosolic mitochondrial DNA (mtDNA) release, which in turn promotes proliferation of hepatocytes by pro-inflammatory response [52]. Cytosolic mitochondrial DNA stress activates TLR9/NFKB/ CCL2 pathway, and then increases TAM (tumor-associated macrophage)-induced HCC [53]. These findings suggest that damaged mitochondrial clearance or lysosomal membrane permeabilization-mediated antigen presentation could enhance anti-tumor immune response (Fig. 3), which contributes to cancer immunotherapy. However, mitophagy inhibition in NLRX1 deficiency inhibits turnover of damaged mitochondria in response to TNF- $\alpha$, leading to inhibition of oxidative phosphorylation (OxPhos)-dependent triple-negative breast cancer cell proliferation and migration [54]. In contrast to mitophagy promotes antigen presentation in colorectal cancer (CRC) [49], in response to LPS or heat stress,
PINK1 and PARK2 inhibits mitochondrial antigen presentation [55]. These discrepancy phenomenon may be derived from different model and conditions.

\section{Autophagy, exosome and immune escape}

Exosomes are cellular secreted vesicles $(30-150 \mathrm{~nm})$ with double-layer membrane, which play an important role in regulating crosstalk between cells [56]. Exosomes are generated from endosome-derived multivesicular bodies (MVBs) without degradation by lysosomes [57]. The membrane PD-L1 protein undergoes endosome cycling, and exosomal PD-L1 is observed in multiple types of cancer cells [58]. Tu et al. have described that the binding of membrane CMTM6 to PD-L1 is required for PD-L1 trafficking to cell surface rather than autophagic degradation in lysosome [40]. In addition to PD-L1 releases extracellular by exosome pathway, CD47 is present on exosome [59-61]. SIRP $\alpha$ (signal-regulatory protein $\alpha$ )/ CD47 immune checkpoint is "don't eat me" signal [62, 63], which inhibits phagocytosis of cancer cells by macrophage [62-64]. CD47 is highly expressed on cancer cells $[65,66]$. The binding of CD47 to the surface SIRP $\alpha$ on macrophage resulting in inhibition of phagocytosis $[62,65]$. Exosomal CD47 decreases pancreatic cancer cell clearance by phagocytes [61], while the relationship of exosomal CD47 with autophagy is still unclear. These findings suggest that autophagy induction could contribute to cancer immunotherapy by PD-L1 or CD47 degradation in lysosome (Fig. 4).

\section{Autophagy negatively or positively regulates immune response against cancer cells}

Autophagy promotes $\mathrm{T}$ cell proliferation and survival, which exhibits ability to maintain ER homeostasis by regulating intracellular calcium stores in T cells, in contrast, autophagy inhibition by deleted ATG5 results in T cell death [67]. Increasing evidence suggests that autophagy induction enhances antigen generation and presentation [20-23]. Activation of autophagy increases antigen presentation of DCs and T cell priming leading to inhibition of tumor growth [20]. In the antigen presenting cells (APCs), autophagy induction generates citrullinated peptides that are antigen presentation of MHC-II on $\mathrm{CD}_{4}^{+}$ $\mathrm{T}$ cells [21]. In response to radiation therapy, autophagy causes loss of its natural ligands of MPR (mannose6-phosphate receptor), which is transferred to cell surface leading to increased T cell killing and CTLA4 antibody immunotherapy in B16F10-bearing tumor model [22]. $\alpha$-TEA ( $\alpha$-tocopheryloxyacetic acid) induces autophagic death in lung cancer cells, and then the release of autophagosome with $\alpha$-TAGS acts as an effective antigen presentation on DCs, subsequently, increases CD8 ${ }^{+}$ $\mathrm{T}$ cell killing to cancer cells [23]. Autophagy activation 


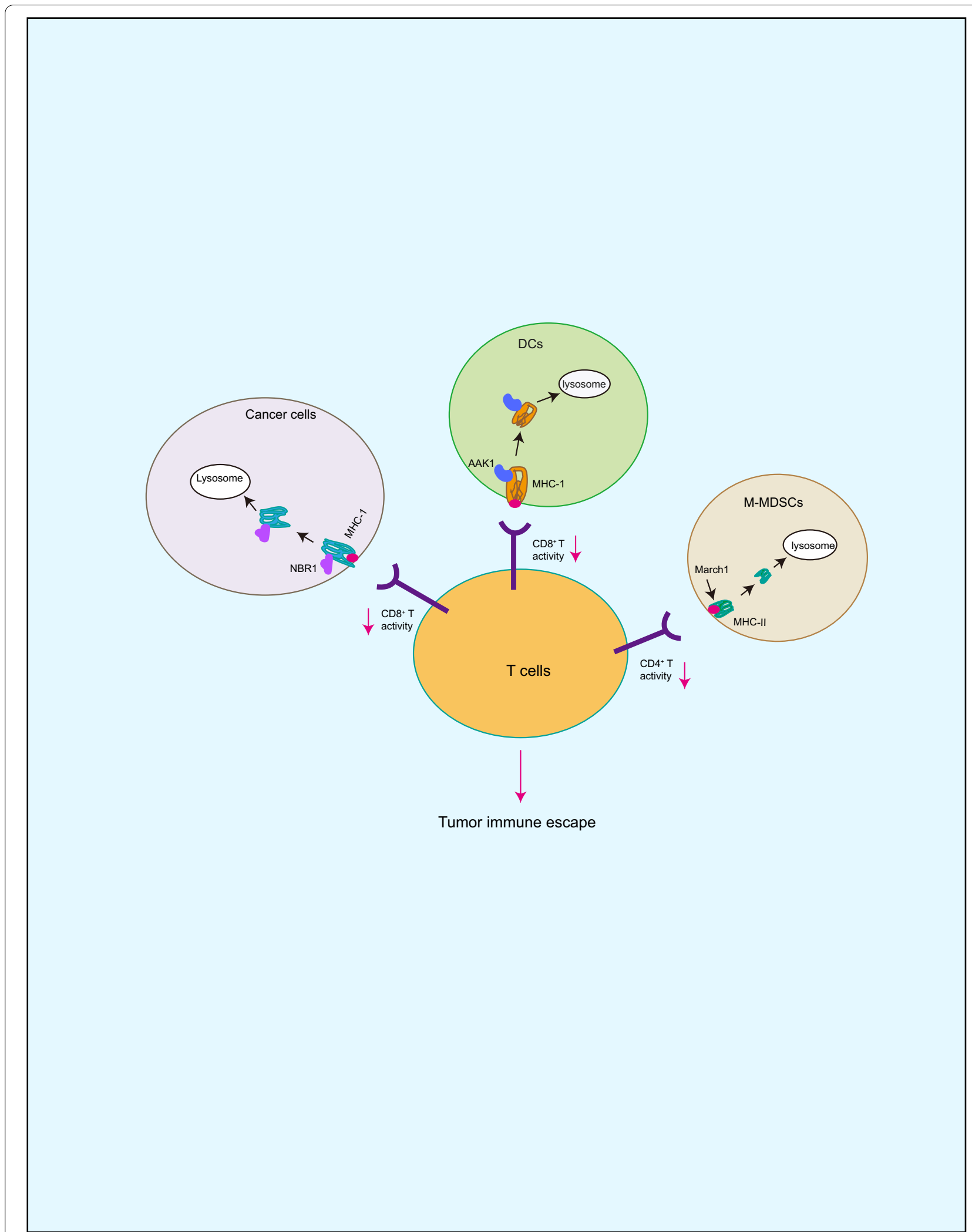

Fig. 2 Autophagy regulates MHC-I/II stability. MHC-1/II plays a critical role in antigen presentation for T cell activation and killing, while MHC-I/ II undergoes autophagic degradation in cancer cells by NBR1 or March1 leading to tumor immune escape. In addition, AAK1 induces MHC-1 autophagic degradation in DCs resulting in inhibition of antigen presentation and T cell activation 


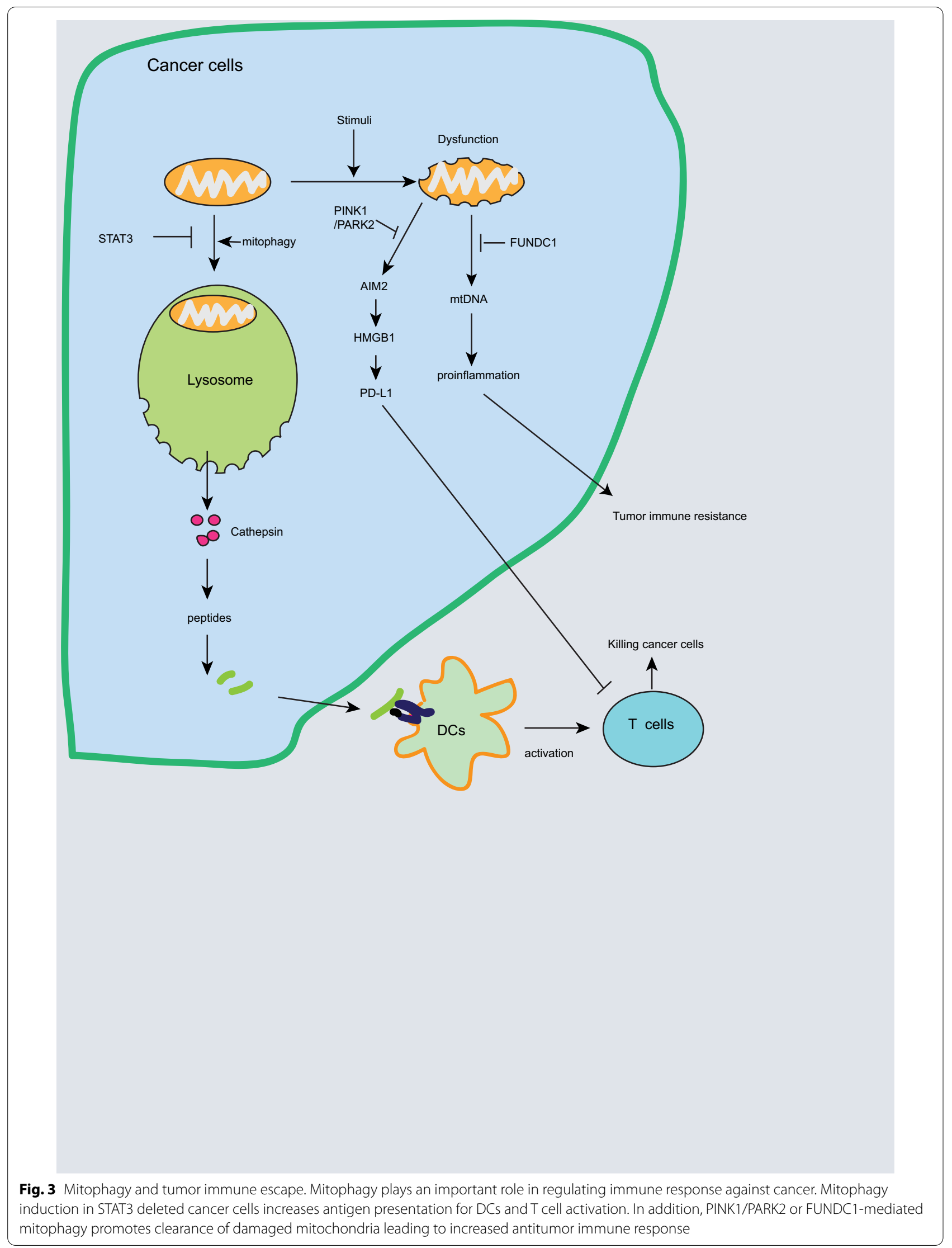




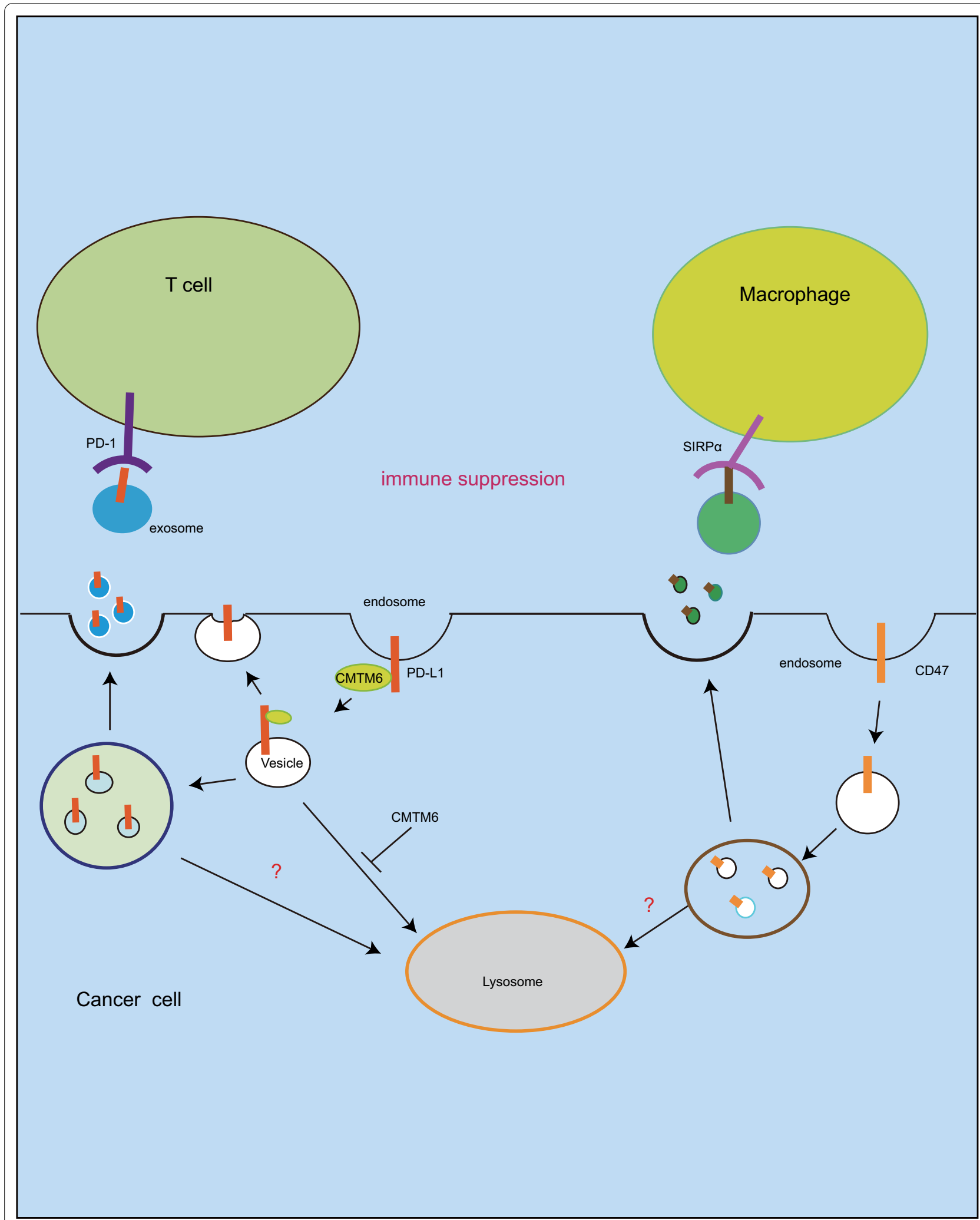

Fig. 4 Autophagy, exosome and immune escape. PD-L1 undergoes endosome and degradation in lysosome, but CMTM6 facilitates endocytosed PD-L1 recycling to membrane. The immune checkpoint protein PD-L1 and CD47 are presented on exosomes, which maybe escape autophagic degradation in lysosome 
(See figure on next page.)

Fig. 5 Autophagy positively or negatively regulates immune response against cancer. Autophagy induction acts as inhibition or promotion of cancer immune escape. This controversial phenomenon may be derived from the experimental context. Some experimental models are in vitro analysis, whereas the regulatory role of autophagy on cancer immune response is complicate in the tumor microenvironment in response to hypoxia, cytokines, or chemotherapy. Autophagy maybe exhibit synergistic effect with immune cells on regulation of cancer immune surveillance

in response to temozolomide and VPA in GL261 glioma cells increases $\mathrm{T}$ cell activity [68]. As a secreted cellular matrix protein, tenascin- $\mathrm{C}$ inhibits $\mathrm{T}$ cell activation, but SKP2 induces tenascin-C ubiquitination and p62-mediated autophagic degradation, in contrast, autophagy deficiency reverses this event resulting in (TNBC) triple-negative breast cancer resistance to $T$ cell [69]. In addition to $\mathrm{T}$ cell activation by autophagy, autophagy induction also increases NK cell killing by HMBOX1 (homeobox containing 1) [70] in HepG2 cells or activation of p53 in breast cancer cells [71]. Chollat-Namy et al. [71] have described that pharmacological reactivation of mutant $\mathrm{p} 53$ by CP31398 results in autophagy induction in breast cancer cells. Mechanistically, CP31398 blocks the infusion of lysosome and autophagosome that contains anti-apoptotic Bcl-Xl, XIAP proteins. In addition, this drug also inhibits granzyme B degradation that is important for NK cell killing. However, activation of mutant p53 by CP31398 is involved in multiple pathways, which maybe have alternative mechanism that is independent of $\mathrm{p} 53$ function for NK activation. These findings suggest that autophagy induction positively regulates immune response against cancer cells (Fig. 5).

In contrast to activation of immune response by autophagy induction, some reports suggest that autophagy induction inhibits $\mathrm{T}$ cell activation in response to EMT (epithelial-to-mesenchymal transition) [72], ROS (reactive oxygen species) [73], and chemotherapy $[24,25]$ leading to impaired T cell killing and promotion of tumor growth, which is associated with autophagymediated antigen degradation $[24,25]$ and inhibition of DCs activity [73] (Fig. 5). Loss of antigen presentation by APCs impairs $\mathrm{T}$ cells priming [74], thus activation of autophagy in macrophages or DCs promotes antigen degradation in lysosome, consequently impairs $\mathrm{T}$ cell killing and promotes MC38 colon cancer growth [24]. Mechanistically, the release of DAMPs (danger-associated molecular patterns) from chemotherapy-induced dying cancer cells increases TIM-4 expression and surface distribution on macrophages and DCs, and then TIM-4 binds to AMPK $\alpha 1$ consequent autophagy induction and antigen degradation in lysosome. Consistently, in response to chemotherapy, treatment with autophagy inhibitor (chloroquine) effectively increases $\mathrm{CD} 8^{+} \mathrm{T}$ cell killing to colon cancer cells [25] and $\mathrm{CD} 4^{+} \mathrm{T}$ cell killing to lung cancer cells [75]. Activation of STING-mediated pro-inflammatory cytokine release could facilitate $\mathrm{T}$ cell priming [74]. Therefore, another report shows that SKIL/TAZ-induced autophagy inhibits STING pathway-mediated antitumor immune response [76]. In this study, it shows that SKIL increases TAZ protein stability by inhibition of LATS2 activity, which in turn promotes autophagy and tumorigenesis of lung cancer. In addition, SKIL/TAZ/autophagy pathway reduces pro-inflammatory cytokine release including CXCL10, CCL5, and IFN$\beta$, which could be activation of STING pathway-mediated antitumor immune response, but the direct relationship of autophagy in NSCLCs with STING pathway is unclear. Autophagy induction reduces IL- $1 \beta$ release [77], which in turn inhibits IL-1/TLR/NFKB-mediated pro-inflammatory cytokine release in macrophages and DCs resulting in impaired $\gamma \delta \mathrm{T}$ cell activation [26]. In contrast, combined chloroquine (autophagy inhibitor) with IL-2 increases IL-1 immunotherapy in metastatic liver tumor model [78]. These findings suggest that autophagy inhibits pro-inflammatory response-mediated antitumor immune therapy. In addition to inhibition of $\mathrm{T}$ cell activity by autophagy, deficiency of autophagy promotes CLL5 expression resulting in NK cell infiltration and tumor growth inhibition of melanomas [79]. In response to hypoxia, autophagy induction causes resistant to NK cell killing by granzyme B autophagic degradation in breast cancer cells [80]. These reports suggest that autophagy induction in APCs or cancer cells impairs immune cell activity such as DCs, T cells and NK cells, which are associated with antigen presentation or granzyme B degradation. These findings suggest autophagy induction negatively regulates immune response against cancer cells (Fig. 5).

\section{Conclusion}

Autophagy induction could enhance effectivity of cancer immune therapy by PD-L1 autophagic degradation in multiple types of cancer cells $[17,34,36$, 37, 39]. Conversely, NBR1 induces MHC-I selective autophagic degradation in PDAC consequent tumor immune escape, while autophagy inhibitor treatment increases the efficiency of anti-tumor immune therapy [18]. Since PD-L1 undergoes endosome trafficking and autophagic degradation in lysosome [35], does autophagy inhibition in PDAC could elevate PD-L1 protein levels? Moreover, internalized CTLA-4 


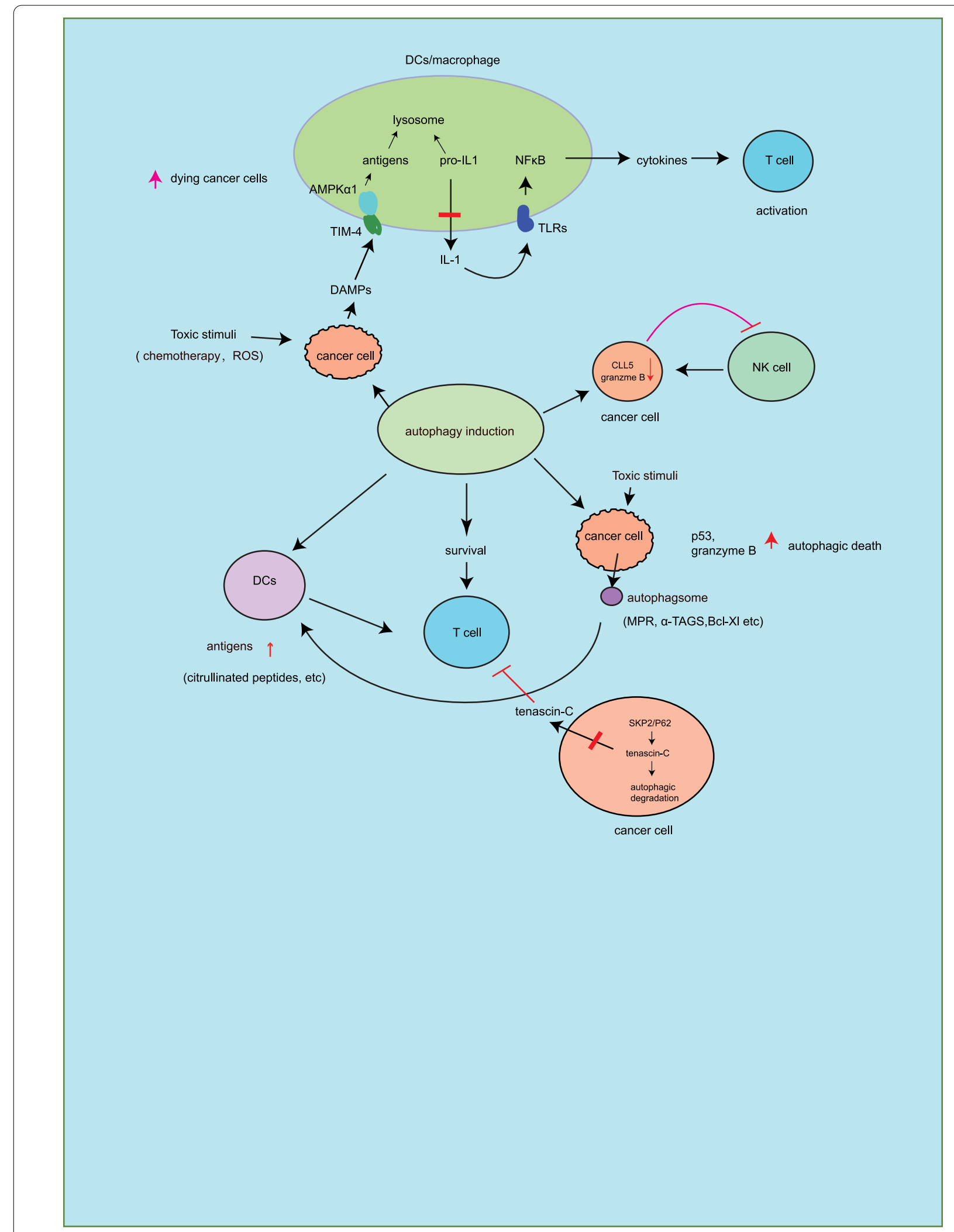

Fig. 5 (See legend on previous page.) 
(cytotoxic T-lymphocyte antige 4) immune checkpoint on $\mathrm{T}$ cells undergoes recycling to the cell surface by binding to LRBA or is sorted to lysosome for degradation [81-84]. However, it is still unclear the mechanism of CTLA-4 autophagic degradation and the effect on cancer immunotherapy. In addition, autophagy induction increases antigens generation and $\mathrm{T}$ cell activation [20-23], while autophagy could degrade antigens in DCs or cancer cells leading to tumor immune escape (Fig. 5). However, autophagy deficiency or inhibition by using autophagy inhibitor chloroquine has no effect on $\mathrm{T}$ cell response in tumor-bearing mice [85]. Therefore, these controversial reports may be derived from different experimental context or models. For example, as an important regulator of autophagy, FIP200 inhibits AZI2/TBK1/IFN pro-inflammatory cytokine expressions, which could increase $\mathrm{CD} 8^{+} \mathrm{T}$ cell activity. However, in this process, FIP200 did not exhibit autophagy function [86]. Thus, it is necessary to determine the direct role of autophagy on cancer immune escape. Some autophagy-related genes could exhibit alternative function without autophagy induction. Moreover, autophagy could maintain the homeostasis of pro-inflammatory innate response [87], this study shows that selective autophagic degradation of TRIF by TAX1BP1 regulates the TRIF/TLR-induced robust proinflammatory immune response in macrophage. Some studies are in vitro analysis. Actually, in tumor microenvironment, autophagy regulates cancer immune escape will be more complicate. Therefore, autophagy maybe regulate the homeostasis of cancer immune response.

\section{Abbreviations}

PD-L1: Programmed death ligand 1; PD-1: Programmed death 1; EMT: Epithelial-mesenchymal transition; GSK3 $\beta$ : Glycogen synthase kinase 3 $\beta$; DHHC3: DHHC-type palmitoyltransferase; NSCLC: Non-small cell lung cancer; 2-BP: 2-Bromopalmitate; APCs: Antigen-presenting cells; MHC: Major histocompatibility complex; M-MDSCs: Myeloid-derived suppressor cells; DCs: Dendritic cells; MVBs: Endosome-derived multivesicular bodies; MPR: Mannose-6-phosphate receptor; CTLA-4: Cytotoxic T-lymphocyte antige 4; LRBA: Lipopolysaccharide-responsive and beige-like anchor.

\section{Acknowledgements}

This work was supported by National Natural Science Foundation of China (82172979, 81972618,81872275).

\section{Authors' contributions}

Y.D., X.T., J.J., Q.L., and Y.H. wrote this manuscript. J.S. corrected this manuscript. All authors read and approved the final manuscript.

\section{Funding}

This work was supported by the National Natural Science Foundation of China (82172979, 81972618, 81872275); Jiangsu Commission of Health Natural Science Foundation (M2020002), Changzhou Sci \& Tech Program. Grant No. CJ20200004.
Availability of data and materials

Not applicable.

\section{Declarations}

Ethics approval and consent to participate

Not applicable.

\section{Consent for publication \\ Not applicable.}

\section{Competing interests}

The authors declare that they have no competing interests.

\section{Author details}

${ }^{1}$ Department of Oncology, The Affiliated Wujin Hospital, Jiangsu University, Changzhou 213017, Jiangsu Province, China. ${ }^{2}$ School of Life Sciences, Jiangsu University, Zhenjiang 213017, Jiangsu Province, China. ${ }^{3}$ Department of Oncology, The Wujin Clinical College of Xuzhou Medical University, Changzhou 213017, Jiangsu Province, China.

Received: 5 April 2021 Accepted: 24 July 2021

Published online: 07 September 2021

\section{References}

1. Kaur J, Debnath J. Autophagy at the crossroads of catabolism and anabolism. Nat Rev Mol Cell Biol. 2015;16:461-72.

2. Chang SH, Huang SW, Wang ST, Chung KC, Hsieh CW, Kao JK, Chen YJ, Wu CY, Shieh JJ. Imiquimod-induced autophagy is regulated by ER stressmediated PKR activation in cancer cells. J Dermatol Sci. 2017;87:138-48.

3. Wen X, Klionsky DJ. An overview of macroautophagy in yeast. J Mol Biol. 2016:428:1681-99.

4. Schuck S. Microautophagy_distinct molecular mechanisms handle cargoes of many sizes. J Cell Sci. 2020;133:jcs246322.

5. Cuervo AM, Wong E. Chaperone-mediated autophagy: roles in disease and aging. Cell Res. 2014;24:92-104.

6. Pankiv S, Clausen TH, Lamark T, Brech A, Bruun JA, Outzen H, Overvatn A, Bjorkoy G, Johansen T. p62/SQSTM1 binds directly to Atg8/LC3 to facilitate degradation of ubiquitinated protein aggregates by autophagy. J Biol Chem. 2007;282:24131-45.

7. Kirkin V, Lamark T, Sou YS, Bjorkoy G, Nunn JL, Bruun JA, Shvets E, McEwan DG, Clausen TH, Wild P, et al. A role for NBR1 in autophagosomal degradation of ubiquitinated substrates. Mol Cell. 2009;33:505-16.

8. Lazarou M, Sliter DA, Kane LA, Sarraf SA, Wang C, Burman JL, Sideris DP, Fogel Al, Youle RJ. The ubiquitin kinase PINK1 recruits autophagy receptors to induce mitophagy. Nature. 2015;524:309-14.

9. Kimmelman AC, White E. Autophagy and Tumor Metabolism. Cell Metab. 2017;25:1037-43.

10. Onorati AV, Dyczynski M, Ojha R, Amaravadi RK. Targeting autophagy in cancer. Cancer. 2018;124(16):3307-18.

11. Singh SS, Vats S, Chia AY, Tan TZ, Deng S, Ong MS, Arfuso F, Yap CT, Goh $B C$, Sethi G, et al. Dual role of autophagy in hallmarks of cancer. Oncogene. 2018;37:1142-58.

12. Gou Q, Jiang Y, Zhang R, Xu Y, Xu H, Zhang W, Shi J, Hou Y. PPARdelta is a regulator of autophagy by its phosphorylation. Oncogene. 2020;39:4844-53.

13. Mancias JD, Kimmelman AC. Targeting autophagy addiction in cancer. Oncotarget. 2011;2:1302-6.

14. Degenhardt K, Mathew R, Beaudoin B, Bray K, Anderson D, Chen G, Mukherjee C, Shi Y, Gelinas C, Fan Y, et al. Autophagy promotes tumor cell survival and restricts necrosis, inflammation, and tumorigenesis. Cancer Cell. 2006;10:51-64.

15. Buchser WJ, Laskow TC, Pavlik PJ, Lin HM, Lotze MT. Cell-mediated autophagy promotes cancer cell survival. Cancer Res. 2012;72:2970-9.

16. Carcereri de Prati A, Butturini E, Rigo A, Oppici E, Rossin M, Boriero D, Mariotto S. Metastatic breast cancer cells enter into dormant state and express cancer stem cells phenotype under chronic hypoxia. J Cell Biochem. 2017;118:3237-48. 
17. Gou Q, Dong C, Xu H, Khan B, Jin J, Liu Q, Shi J, Hou Y. PD-L1 degradation pathway and immunotherapy for cancer. Cell Death Dis. 2020;1 1:955.

18. Yamamoto K, Venida A, Yano J, Biancur DE, Kakiuchi M, Gupta S, Sohn ASW, Mukhopadhyay S, Lin EY, Parker SJ, et al. Autophagy promotes immune evasion of pancreatic cancer by degrading MHC-I. Nature. 2020;581:100-5

19. Hegde PS, Chen DS. Top 10 challenges in cancer immunotherapy. Immunity. 2020;52:17-35.

20. Wang Y, Lin YX, Wang J, Qiao SL, Liu YY, Dong WQ, Wang J, An HW, Yang C, Mamuti $M$, et al. In situ manipulation of dendritic cells by an autophagyregulative nanoactivator enables effective cancer immunotherapy. ACS Nano. 2019;13:7568-77.

21. Ireland JM, Unanue ER. Autophagy in antigen-presenting cells results in presentation of citrullinated peptides to CD4 T cells. J Exp Med. 2011;208:2625-32.

22. Kim S, Ramakrishnan R, Lavilla-Alonso S, Chinnaiyan P, Rao N, Fowler E, Heine J, Gabrilovich DI. Radiation-induced autophagy potentiates immunotherapy of cancer via up-regulation of mannose 6-phosphate receptor on tumor cells in mice. Cancer Immunol Immunother. 2014;63:1009-21.

23. Li Y, Hahn T, Garrison K, Cui ZH, Thorburn A, Thorburn J, Hu HM, Akporiaye ET. The vitamin E analogue alpha-TEA stimulates tumor autophagy and enhances antigen cross-presentation. Cancer Res. 2012;72:3535-45.

24. Baghdadi M, Yoneda A, Yamashina T, Nagao H, Komohara Y, Nagai S, Akiba H, Foretz M, Yoshiyama H, Kinoshita I, et al. TIM-4 glycoprotein-mediated degradation of dying tumor cells by autophagy leads to reduced antigen presentation and increased immune tolerance. Immunity. 2013:39:1070-81.

25. Zamame Ramirez JA, Romagnoli GG, Falasco BF, Gorgulho CM, Sanzochi Fogolin C, Dos Santos DC, Junior JPA, Lotze MT, Ureshino RP, Kaneno R. Blocking drug-induced autophagy with chloroquine in HCT-116 colon cancer cells enhances DC maturation and T cell responses induced by tumor cell lysate. Int Immunopharmacol. 2020;84:106495.

26. Peral de Castro C, Jones SA, Cheallaigh CN, Hearnden CA, Williams L, Winter J, Lavelle EC, Mills KH, Harris J. Autophagy regulates IL-23 secretion and innate $T$ cell responses through effects on IL-1 secretion. J Immunol. 2012:189:4144-53.

27. Topalian SL, Drake CG, Pardoll DM. Targeting the PD-1/B7-H1 (PDL1) pathway to activate anti-tumor immunity. Curr Opin Immunol. 2012;24:207-12.

28. Yokosuka T, Takamatsu M, Kobayashi-Imanishi W, Hashimoto-Tane A Azuma M, Saito T. Programmed cell death 1 forms negative costimulatory microclusters that directly inhibit $\mathrm{T}$ cell receptor signaling by recruiting phosphatase SHP2. J Exp Med. 2012;209:1201-17.

29. Yarchoan M, Hopkins A, Jaffee EM. Tumor mutational burden and response rate to PD-1 inhibition. N Engl J Med. 2017;377:2500-1.

30. Iwai Y, Hamanishi J, Chamoto K, Honjo T. Cancer immunotherapies targeting the PD-1 signaling pathway. J Biomed Sci. 2017;24:26

31. Topalian SL, Drake CG, Pardoll DM. Immune checkpoint blockade: a common denominator approach to cancer therapy. Cancer Cell. 2015;27:450-61.

32. Wang H, Yao H, Li C, Shi H, Lan J, Li Z, Zhang Y, Liang L, Fang JY, Xu J. HIP1R targets PD-L1 to lysosomal degradation to alter T cell-mediated cytotoxicity. Nat Chem Biol. 2019;15:42-50.

33. Li CW, Lim SO, Chung EM, Kim YS, Park AH, Yao J, Cha JH, Xia W, Chan LC, Kim T, et al. Eradication of Triple-Negative Breast Cancer Cells by Targeting Glycosylated PD-L1. Cancer Cell. 2018;33:187-201.

34. Yao H, Lan J, Li C, Shi H, Brosseau JP, Wang H, Lu H, Fang C, Zhang Y, Liang L, et al. Inhibiting PD-L1 palmitoylation enhances T-cell immune responses against tumours. Nat Biomed Eng. 2019;3:306-17.

35. Burr ML, Sparbier CE, Chan YC, Williamson JC, Woods K, Beavis PA, Lam EYN, Henderson MA, Bell CC, Stolzenburg S, et al. CMTM6 maintains the expression of PD-L1 and regulates anti-tumour immunity. Nature. 2017;549:101-5.

36. Zhang N, Dou Y, Liu L, Zhang X, Liu X, Zeng Q, Liu Y, Yin M, Liu X, Deng $H$, Song D. SA-49, a novel aloperine derivative, induces MITF-dependent lysosomal degradation of PD-L1. EBioMedicine. 2019;40:151-62.

37. Maher CM, Thomas JD, Haas DA, Longen CG, Oyer HM, Tong JY, Kim FJ. Small-molecule Sigma1 modulator induces autophagic degradation of PD-L1. Mol Cancer Res. 2018;16:243-55.

38. Liang J, Wang L, Wang C, Shen J, Su B, Marisetty AL, Fang D, Kassab C, Jeong KJ, Zhao W, et al. Verteporfin inhibits PD-L1 through autophagy and the STAT1-IRF1-TRIM28 signaling axis, exerting antitumor efficacy. Cancer Immunol Res. 2020;8:952-65.

39. Li H, Kuang X, Liang L, Ye Y, Zhang Y, Li J, Ma F, Tao J, Lei G, Zhao S, et al. The beneficial role of sunitinib in tumor immune surveillance by regulating tumor PD-L1. Adv Sci (Weinh). 2021;8:2001596.

40. Tu X, Qin B, Zhang Y, Zhang C, Kahila M, Nowsheen S, Yin P, Yuan J, Pei H, $\mathrm{Li} H$, et al. PD-L1 (B7-H1) competes with the RNA exosome to regulate the DNA damage response and can be targeted to sensitize to radiation or chemotherapy. Mol Cell. 2019;74:1215-26.

41. Liu Y, Zhang H, Wang Z, Wu P, Gong W. 5-Hydroxytryptamine1a receptors on tumour cells induce immune evasion in lung adenocarcinoma patients with depression via autophagy/pSTAT3. Eur J Cancer. 2019:114:8-24.

42. Janji B, Hasmim M, Parpal S, De Milito A, Berchem G, Noman MZ. Lighting up the fire in cold tumors to improve cancer immunotherapy by blocking the activity of the autophagy-related protein PIK3C3/NPS34. Autophagy. 2020;16:2110-1.

43. Balkwill F, Mantovani A. Inflammation and cancer: back to Virchow? Lancet. 2001;357:539-45.

44. Galon J, Mlecnik B, Bindea G, Angell HK, Berger A, Lagorce C, Lugli A, Zlobec I, Hartmann A, Bifulco C, et al. Towards the introduction of the "Immunoscore" in the classification of malignant tumours. J Pathol. 2014;232:199-209.

45. Alissafi T, Hatzioannou A, Mintzas K, Barouni RM, Banos A, Sormendi S, Polyzos A, Xilouri M, Wielockx B, Gogas H, Verginis P. Autophagy orchestrates the regulatory program of tumor-associated myeloid-derived suppressor cells. J Clin Investig. 2018;128:3840-52.

46. Zeng H, Zhang W, Gong Y, Xie C. Radiotherapy activates autophagy to increase CD8(+) T cell infiltration by modulating major histocompatibility complex class-l expression in non-small cell lung cancer. J Int Med Res. 2019:47:3818-30.

47. Loi M, Muller A, Steinbach K, Niven J, da Silva RB, Paul P, Ligeon LA, Caruso A, Albrecht RA, Becker AC, et al. Macroautophagy proteins control MHC class i levels on dendritic cells and shape anti-viral CD8(+) T cell responses. Cell Rep. 2016;15:1076-87.

48. Chourasia AH, Boland ML, Macleod KF. Mitophagy and cancer. Cancer Metab. 2015:3:4.

49. Ziegler PK, Bollrath J, Pallangyo CK, Matsutani T, Canli O, De Oliveira T, Diamanti MA, Muller N, Gamrekelashvili J, Putoczki T, et al. Mitophagy in intestinal epithelial cells triggers adaptive immunity during tumorigenesis. Cell. 2018;174:88-101.

50. Bernardini JP, Lazarou M, Dewson G. Parkin and mitophagy in cancer. Oncogene. 2017;36:1315-27.

51. Li C, Zhang Y, Cheng X, Yuan H, Zhu S, Liu J, Wen Q, Xie Y, Liu J, Kroemer $G$, et al. PINK1 and PARK2 suppress pancreatic tumorigenesis through control of mitochondrial iron-mediated immunometabolism. Dev Cell. 2018:46:441-55.

52. Li W, Li Y, Siraj S, Jin H, Fan Y, Yang $X$, Huang $X$, Wang $X$, Wang J, Liu L, et al. FUN14 domain-containing 1-mediated mitophagy suppresses hepatocarcinogenesis by inhibition of inflammasome activation in mice. Hepatology. 2019;69:604-21.

53. Bao D, Zhao J, Zhou X, Yang Q, Chen Y, Zhu J, Yuan P, Yang J, Qin T, Wan $\mathrm{S}$. Xing J. Mitochondrial fission-induced mtDNA stress promotes tumorassociated macrophage infiltration and HCC progression. Oncogene. 2019:38:5007-20.

54. Singh K, Roy M, Prajapati P, Lipatova A, Sripada L, Gohel D, Singh A, Mane M, Godbole MM, Chumakov PM, Singh R. NLRX1 regulates TNF-alphainduced mitochondria-lysosomal crosstalk to maintain the invasive and metastatic potential of breast cancer cells. Biochim Biophys Acta Mol Basis Dis. 2019;1865:1460-76.

55. Matheoud D, Sugiura A, Bellemare-Pelletier A, Laplante A, Rondeau C, Chemali M, Fazel A, Bergeron JJ, Trudeau LE, Burelle Y, et al. Parkinson's disease-related proteins PINK1 and Parkin repress mitochondrial antigen presentation. Cell. 2016;166:314-27.

56. Colombo M, Raposo G, Thery C. Biogenesis, secretion, and intercellular interactions of exosomes and other extracellular vesicles. Annu Rev Cell Dev Biol. 2014;30:255-89.

57. Xu J, Camfield R, Gorski SM. The interplay between exosomes and autophagy_-partners in crime. J Cell Sci. 2018;131:jcs215210. 
58. Zhou K, Guo S, Li F, Sun Q, Liang G. Exosomal PD-L1: new insights into tumor immune escape mechanisms and therapeutic strategies. Front Cell Dev Biol. 2020;8:569219.

59. Kibria G, Ramos EK, Lee KE, Bedoyan S, Huang S, Samaeekia R, Athman JJ, Harding CV, Lotvall J, Harris L, et al. A rapid, automated surface protein profiling of single circulating exosomes in human blood. Sci Rep. 2016;6:36502.

60. Wang M, Ji S, Shao G, Zhang J, Zhao K, Wang Z, Wu A. Effect of exosome biomarkers for diagnosis and prognosis of breast cancer patients. Clin Transl Oncol. 2018;20:906-11.

61. Kamerkar S, LeBleu VS, Sugimoto H, Yang S, Ruivo CF, Melo SA, Lee JJ, Kalluri R. Exosomes facilitate therapeutic targeting of oncogenic KRAS in pancreatic cancer. Nature. 2017:546:498-503.

62. Jaiswal S, Jamieson CH, Pang WW, Park CY, Chao MP, Majeti R, Traver D, van Rooijen N, Weissman IL. CD47 is upregulated on circulating hematopoietic stem cells and leukemia cells to avoid phagocytosis. Cell. 2009;138:271-85.

63. Majeti R, Chao MP, Alizadeh AA, Pang WW, Jaiswal S, Gibbs KD Jr, van Rooijen N, Weissman IL. CD47 is an adverse prognostic factor and therapeutic antibody target on human acute myeloid leukemia stem cells. Cell. 2009;138:286-99.

64. Casey SC, Tong L, Li Y, Do R, Walz S, Fitzgerald KN, Gouw AM, Baylot V, Gutgemann I, Eilers M, Felsher DW. MYC regulates the antitumor immune response through CD47 and PD-L1. Science. 2016;352:227-31.

65. Brown EJ, Frazier WA. Integrin-associated protein (CD47) and its ligands. Trends Cell Biol. 2001;11:130-5.

66. Yanagita T, Murata Y, Tanaka D, Motegi SI, Arai E, Daniwijaya EW, Hazama D, Washio K, Saito Y, Kotani T, et al. Anti-SIRPalpha antibodies as a potential new tool for cancer immunotherapy. JCI Insight. 2017;2:e89140.

67. Pua HH, Dzhagalov I, Chuck M, Mizushima N, He YW. A critical role for the autophagy gene Atg5 in T cell survival and proliferation. J Exp Med. 2007;204:25-31.

68. Proske J, Walter L, Bumes E, Hutterer M, Vollmann-Zwerenz A, Eyupoglu IY, Savaskan NE, Seliger C, Hau P, Uhl M. Adaptive immune response to and survival effect of temozolomide- and valproic acid-induced autophagy in glioblastoma. Anticancer Res. 2016;36:899-905.

69. Li ZL, Zhang HL, Huang Y, Huang JH, Sun P, Zhou NN, Chen YH, Mai J, Wang $Y, Y u$ Y, et al. Autophagy deficiency promotes triple-negative breast cancer resistance to $T$ cell-mediated cytotoxicity by blocking tenascin-C degradation. Nat Commun. 2020;11:3806.

70. Zhao H, Jia H, Han Q, Zhang J. Homeobox containing 1 inhibits liver cancer progression by promoting autophagy as well as inhibiting stemness and immune escape. Oncol Rep. 2018;40:1657-65.

71. Chollat-Namy M, Ben Safta-Saadoun T, Haferssas D, Meurice G, Chouaib S, Thiery J. The pharmalogical reactivation of p53 function improves breast tumor cell lysis by granzyme B and NK cells through induction of autophagy. Cell Death Dis. 2019;10:695.

72. Akalay I, Janji B, Hasmim M, Noman MZ, Andre F, De Cremoux P, Bertheau P, Badoual C, Vielh P, Larsen AK, et al. Epithelial-to-mesenchymal transition and autophagy induction in breast carcinoma promote escape from T-cell-mediated lysis. Cancer Res. 2013;73:2418-27.

73. Garg AD, Dudek AM, Ferreira GB, Verfaillie T, Vandenabeele P, Krysko DV, Mathieu C, Agostinis P. ROS-induced autophagy in cancer cells assists in evasion from determinants of immunogenic cell death. Autophagy. 2013;9:1292-307.

74. von Roemeling CA, Wang Y, Qie Y, Yuan H, Zhao H, Liu X, Yang Z, Yang M, Deng W, Bruno KA, et al. Therapeutic modulation of phagocytosis in glioblastoma can activate both innate and adaptive antitumour immunity. Nat Commun. 2020;11:1508.

75. Zarogoulidis P, Petanidis S, Domvri K, Kioseoglou E, Anestakis D, Freitag L, Zarogoulidis K, Hohenforst-Schmidt W, Eberhardt W. Autophagy inhibition upregulates CD4(+) tumor infiltrating lymphocyte expression via miR-155 regulation and TRAIL activation. Mol Oncol. 2016;10:1516-31.

76. Ma F, Ding MG, Lei YY, Luo LH, Jiang S, Feng YH, Liu XL. SKIL facilitates tumorigenesis and immune escape of NSCLC via upregulating TAZ/ autophagy axis. Cell Death Dis. 2020;11:1028.

77. Shi CS, Shenderov K, Huang NN, Kabat J, Abu-Asab M, Fitzgerald KA, Sher A, Kehrl JH. Activation of autophagy by inflammatory signals limits IL-1 beta production by targeting ubiquitinated inflammasomes for destruction. Nat Immunol. 2012;13:255-63.

78. Liang X, De Vera ME, Buchser WJ, de Vivar Chavez AR, Loughran P, Stolz DB, Basse P, Wang T, Van Houten B, Zeh HJ 3rd, Lotze MT. Inhibiting systemic autophagy during interleukin 2 immunotherapy promotes long-term tumor regression. Cancer Res. 2012;72:2791-801.

79. Mgrditchian T, Arakelian T, Paggetti J, Noman MZ, Viry E, Moussay E, Van Moer K, Kreis S, Guerin C, Buart S, et al. Targeting autophagy inhibits melanoma growth by enhancing NK cells infiltration in a CCL5-dependent manner. Proc Natl Acad Sci U S A. 2017;114:E9271-9.

80. Baginska J, Viry E, Berchem G, Poli A, Noman MZ, van Moer K, Medves S, Zimmer J, Oudin A, Niclou SP, et al. Granzyme B degradation by autophagy decreases tumor cell susceptibility to natural killer-mediated lysis under hypoxia. Proc Natl Acad Sci U S A. 2013;110:17450-5.

81. Qureshi OS, Kaur S, Hou TZ, Jeffery LE, Poulter NS, Briggs Z, Kenefeck R, Willox AK, Royle SJ, Rappoport JZ, Sansom DM. Constitutive clathrinmediated endocytosis of CTLA-4 persists during T cell activation. J Biol Chem. 2012;287:9429-40.

82. lida T, Ohno H, Nakaseko C, Sakuma M, Takeda-Ezaki M, Arase H, Kominami E, Fujisawa T, Saito T. Regulation of cell surface expression of CTLA-4 by secretion of CTLA-4-containing lysosomes upon activation of CD4+ T cells. J Immunol. 2000;165:5062-8.

83. Lo B, Zhang K, Lu W, Zheng L, Zhang Q, Kanellopoulou C, Zhang Y, Liu Z, Fritz JM, Marsh R, et al. AUTOIMMUNE DISEASE. Patients with LRBA deficiency show CTLA4 loss and immune dysregulation responsive to abatacept therapy. Science. 2015;349:436-40.

84. Janman D, Hinze C, Kennedy A, Halliday N, Waters E, Williams C, Rowshanravan B, Hou TZ, Minogue S, Qureshi OS, Sansom DM. Regulation of CTLA-4 recycling by LRBA and Rab11. Immunology. 2021;164(1):106-19.

85. Starobinets H, Ye J, Broz M, Barry K, Goldsmith J, Marsh T, Rostker F, Krummel M, Debnath J. Antitumor adaptive immunity remains intact following inhibition of autophagy and antimalarial treatment. J Clin Investig. 2016;126:4417-29.

86. Okamoto T, Yeo SK, Hao M, Copley MR, Haas MA, Chen S, Guan JL. FIP200 suppresses immune checkpoint therapy responses in breast cancers by limiting AZI2/TBK1/IRF signaling independent of its canonical autophagy function. Cancer Res. 2020;80:3580-92.

87. Samie M, Lim J, Verschueren E, Baughman JM, Peng I, Wong A, Kwon Y, Senbabaoglu Y, Hackney JA, Keir M, et al. Selective autophagy of the adaptor TRIF regulates innate inflammatory signaling. Nat Immunol. 2018;19:246-54.

\section{Publisher's Note}

Springer Nature remains neutral with regard to jurisdictional claims in published maps and institutional affiliations. 